\title{
“Can We Learn Martial Arts Through Books?": The Revival of Korean Fight Books Through Transmission and Reconstruction
}

\author{
Bok Kyu Choi \\ Korean Institute for Martial Arts \\ choibokkyu@gmail.com
}

\begin{abstract}
Fight books can be defined as texts specialising in the theories of martial arts and the instruction of techniques (for future generations) based on actual experience of real fighting and training. According to this definition, today's efforts to reconstruct classical martial arts based upon historic fight books, in both East and West, are attempts to resurrect something extinct. Traditional East Asian martial artists, however, often argue that there are substantial limits in the reconstruction process of, for example, medieval European martial arts given the discontinuity of embodied knowledge, especially when compared to the Asian arts' presumed strong transmission from generation to generation without interruption. Both seem quite different, but they share the epistemological assumption that authentic archetypes of martial arts did exist at some point in the past and believe it possible to transmit or reconstruct them in the present. This paper examines the limitations to the hypothesis of the existence of martial arts archetypes by examining the discourse surrounding the inherited tradition of the Muyedobotongji in Korea. The authors of the Muyedobotongji successfully synthesised and standardised contemporary East Asian martial arts and shared that knowledge from the perspective of Joseon ${ }^{1}$ in the late eighteenth century. Now, after 200 years, we must do our part to breathe new life into it for this era.
\end{abstract}

Keywords: martial arts studies, fight books, invented martial arts, tradition, authenticity, Korean martial arts

\section{CAN WE LEARN MARTIAL ARTS THROUGH BOOKS?}

One question that has mesmerised me for a very long time is "can we learn martial arts through books?". As a teenager I was drawn to the secretive "martial arts manuals" referred to in martial arts films and novels and was more fascinated by the idea of learning these arts through those books rather than the story. I often wondered whether it would be possible to become a master if only I had the secret manual. Subsequently, I obtained

\footnotetext{
1 The Joseon Dynasty, also known as the Chosun Dynasty, was a dynasty that ruled the Korean peninsula for 505 years from 1392 to 1897 . The Joseon Dynasty was the longest ruling dynasty in Korean history, and adopted Confucianism as its political doctrine.
} 
a Chinese martial arts manual and tried to learn techniques from it, but within a week I quit - disillusioned with the hope that it was even possible to do so.

Forty years have passed since then, and although I did not become a master like those in the films, my dream still came true! I now lead a life of researching the history of martial arts, reading classical fight books, and reconstructing their techniques. Encountering the Muyedobotongii in my twenties changed my life. The Muyedobotongji was both a secretive manual that could help me to become a "superman" and a door that led not only to classical Korean martial arts, but also to all of the other East Asian classical martial arts.

The Muyedobotongiz, compiled in 1790 on the order of King Jeongjo (r. 1776-1800), himself a member of the Joseon Dynasty of Korea, became well-known to the Korean public only as recently as the 1980s. The first modern Korean translation of the Muyedobotongji, which was originally written in classical Chinese and ancient Korean, was published in 1984. In 1987 Kim Gwang-suk (1936-2018), who was considered the direct successor to the martial arts of the Muyedobotongij, popularised the text by publishing his Practical Analysis of Muyedobotongii and conducting a live demonstration in a theatre. ${ }^{2}$ Although Kim Gwang-suk's works proved popular, the voices that supported Korea's authentic martial arts grew louder: the Muyedobotongii was not considered to be a book of authentic Korean martial arts by many followers of indigenous Korean martial arts, and they considered most of its techniques nothing more than a copy of Japanese and Chinese martial arts manuals. They further argued that Kim was not the rightful successor to the Muyedobongii but only re-created the martial arts in the Muyedobotongii based on Chinese models. ${ }^{3}$ In these circumstances appeared a martial arts practitioner named Lim Dong-gyu, who himself claimed that he had reconstructed the martial arts of the Muyedobotongii during his incarceration. ${ }^{4}$

The Muyedobotongii has proven itself a controversial text. There are sharp divisions in Korean society between those who view the Muyedobotongï as a testimony to authentic, traditional Korean martial arts and those who see it as a copy of Chinese originals. Only the authenticity of the Muyedobotongjis tradition was disputed, however, and no other productive debates have emerged regarding the general view of Korean martial arts within the wider context of the history of East Asian martial arts. ${ }^{5}$ Thirty years have now passed and in 2017 the Muyedobotongii was officially registered as a UNESCO Memory of the

\footnotetext{
2 Shin, Mudeok, pp. 465-475.

3 Yuk, Jungguk. Musul Bekein Muyedobotongij.

${ }^{4}$ Lim, Hangukui Jeontong Muye.

${ }^{5}$ Park, Joseon Hugi Muyesa Yongu; Choi, Historical Background of Muyedobotongij.
} 
World. ${ }^{6}$ Both nominally and virtually, the Muyedobotongii is recognised as a true piece of scripture representative of authentic Korean and East Asian martial arts. ${ }^{7}$

While there is widespread belief in an uninterrupted continuity of the martial arts tradition of East Asia, there are still epistemological questions that remain. This is because embodied knowledge assumed in the tradition, as well as the belief that it has been transmitted from generation to generation down to the present day, are presumed to render this knowledge immutable. Documented records of genealogy, techniques, or even the presence of a successor, however, do not guarantee that martial arts today are consistent with martial arts at any point in the past. The argument, based on the belief of the existence of the martial arts archetype, needs to be reviewed because it denies an evolutionary view of martial arts development.

Martial arts are not taxidermal specimens but living concepts. They have evolved through real fighting and training experiences, and the emergence of outstanding individuals and new schools in this process has been an important accelerating force for the evolution of martial arts. So, if there is a historically transmitted martial art without interruption, is it more authentic than today's reconstructions such as, for example, the medieval swordsmanship reconstructed by Historical European Martial Arts (HEMA)?

In this paper, I examine the development of martial arts as part of the history of civilisations through the medium of fight books. The Muyedobotongii has been brought to the light of today's world and has established itself as a classic scripture of martial arts. As a text, however, the Muyedobotongii should still be deconstructed and analysed. I will first review the Muyedobotongi from the perspective of martial arts history, and secondly explore the debate between transmission and reconstruction in the contemporary Korean martial arts community. The analysis will focus on contemporary attempts to bring classical Korean martial arts to life and the surrounding discourse.

${ }^{6}$ The UNESCO project, however, was seemingly manipulated for a political agenda to make ITF Taekwondo traditional. According to the nomination form submitted by Kim Young-ae, section chief of National Library of Democratic People's Republic of Korea (North Korea), "Muyedobotongii, printed on April, 1790, is a comprehensive martial arts book that explains, with respective illustrations, the Korean traditional martial arts which became the origin of Taekwon-do, the international martial arts of today." Kim, Nomination Form, p. 1.

7 There is only one English translation available. It sold 75,000 copies worldwide, which is highly unusual for a martial arts book. The translation is even used as course material in Korean studies at Harvard University and Stanford University. The Joseon Ilbo, on 10.05.2002. 


\section{THE ARCHAEOLOGY OF THE MUYEDOBOTONGJI}

Compared to the situation in Korea in the 1980s and 1990s, the current public recognition of the Muyedobotongii as a scripture of Korean martial arts is remarkable. In the 1980s and 1990s the Muyedobotongii was subject to the critique that it was just a simple copy of Chinese fight books, such as Jixiaoxinsh $u^{8}$ and $W u b e i z h \imath^{9}$, whereas today it is it is recognised as a vital part of Korean martial arts heritage.

This earlier viewpoint appeared to have arisen primarily due to a lack of understanding of the universality of martial arts in East Asia and a failure to accurately recognise the distinct position of the Muyedobotongii in East Asian martial arts history. In fact, the locality of martial arts was recognised even by the late eighteenth century when the Muyedobotongji was written, but this ubiquity of martial arts throughout East Asia was a way to explain unique regional specificities, unlike today's approach of identifying Korean, Japanese, and Chinese martial arts by national borders. Thus, when compiling the Muyedobotongij, there was no hesitation in accepting and accommodating martial arts from various regions for the establishment of an improved martial arts system.

In fact, much of the Muyedobotongii was indeed drawn from Japanese and Chinese martial arts traditions. The unique authenticity of the Muyedobotongii was achieved by incorporating the best practices of those martial arts - judged by the Joseon military into the composition of Joseon's own martial arts system, and furthermore to reorganise it differently than the contemporary fight books of neighbouring countries. Although the Muyedobotongji owes its contents to other sources, it was nevertheless an unprecedented upgrade of East Asian martial arts due to how it systematically overcame the limitations of the existing fight books..$^{10}$

${ }^{8}$ Jixiaoxinshu, or New Book of Effective Discipline is a book of military tactics compiled by a Ming Chinese general, Qi Jiguang (1528-1588). He developed a new type of tactics, called Zhejiang tactics, while defending Zhejiang province against the threats of Japanese pirates (wakou). Zhejiang tactics combine firearms with an infantry formation called the Mandarin Duck Formation, which is organised around groups of twelve soldiers armed with traditional close combat weapons such as shields, thorny spears, long spears, tridents, and staffs. Choi, Gwonbeop Baibeul, pp. 50-60.

9 Wubeizhi, or Treatise on Armament Technology is the most comprehensive military book in China. It was edited by the military officer Mao Yuanyi (1594-1640) and published in 1621. It is composed of 240 volumes, in which its contents related to ancient martial arts are collected in volumes 84 to 92. Most of them are extracted from other sources, mainly Jixiaoxinshu. Exceptionally, the staff method came from the Shaolin Gunfa Chanzong (Expostion of Shaolin Staff Methods), which was written by Cheng Zongyou (1561-?), who studied it at Shaolin temple. Furthermore, it also includes the Joseon sebeop (Chaoxian Shifa in Chinese), which is collected from Joseon, and ancient double-edged swordsmanship. Editorial Committee of Zhongguo Wushu Dacidian, Zhongguo Wushu, p. 495; Kim, Bongukgeon.

10 Before the Muyedobotongji, various fight books existed but they only partially covered different martial arts, such as only swordsmanship, staff, or spear. Some military manuals have a selection of arts, but in this case still they have a collection of individual techniques without complete diagrams, or charts (such as Jixiaoxinshu), which is crucial in the ancient military training of Asian tradition. 
The Muyedobotongii is a practical manual of classical martial arts. Since martial arts also have a social component, however, an awareness of the historical context is crucial for our understanding of the Muyedobotongji. As such, it is vital to understand how the Muyedobotongii was compiled, and how the respective martial arts were selected and recorded.

The Muyedobotongii is not a document that spontaneously appeared in the late eighteenth century, but one that inherited the traditions of earlier fight books, including the 1598 Muyejebo ${ }^{11}$ (Illustrated Manual of Martial Arts), the 1610 Muyejebo Beonyeok Sokjip ${ }^{12}$ (Translated Sequel to Illustrated Manual of Martial Arts), and the 1759 Muyesinbo (New Illustrated Manual of Martial Arts). The Joseon Kingdom of that era inherited the tradition of martial arts from previous generations and synthesised and revised the martial arts of its day to create the Muyedobotongii as the final version of Joseon's fight book. This means that an archaeological exploration of martial arts is possible as one can trace the processes involved in the compilation of the fight books, and in doing so it is possible to comprehend the reality of classical martial arts.

The creation of the Muyejebo marks the beginning of fight book compilation in Korea. The Japanese invasions of Korea in 1592-1598, as part of the Imjin War, directly triggered their appearance. The Japanese invasions were the biggest wars in East Asia during the late sixteenth century, where Japan confronted the allied forces of Joseon and China in Joseon lands. Before the war, Joseon's military had adopted a tactical approach based on battle formations combined with cavalry. Usually the battle would begin at distance where firearms and archery could be employed, and battle would only gradually progress into hand-to-hand combat involving cavalry. Such methods proved effective in the absence of the threat of a total war as well as Joseon's need to only deal with small-scale local attacks. Against the Japanese invasions, however, these tactics no longer worked as well because the Japanese troops were armed with arquebuses. The arquebus was introduced to Japan in 1543, where it became an important weapon during the Japanese Warring States period (1467-1573). It went on to play an increasingly important role during the Japanese invasions as the arquebus has both a longer shooting range and greater accuracy than the Korean bow, thus neutralising it. In combination with the use of the arquebuses, Japanese

From this perspective, the Muyedobotongii overcomes the limitations the preceding fight books by selecting, collecting, and synthesising the whole system of close combat arts, even including an equestrian application. Such a huge collection inevitably required a new categorisation system to clarify the arts effectively, so the Muyedobotongji adopted three categories: thrusting (long spear, trident, etc.), cutting (long sabre, falchion, etc.), and striking (gwonbeop, staff, flail, etc.).

11 The first fight book of Korea was known to the public as a microfilm in 1990s in Korea. The original copy is in the Institut National des Langues et Civilisations Orientales in Paris (Choi, Gwonbeop Baibeul, p. 30). Recently, another original copy of Muyejebo was found in Korea. The Kyeonggi Ilbo, on 15.11.2018.

12 The second fight book of Korea is held at Dongsan Library of Keimyung University in Korea. It was registered as a national treasure of Republic of Korea in 2001. 
close combat techniques for spearmanship and swordsmanship - both traditional Japanese specialties - reigned supreme on the battlefield. The arquebusiers would fire first, and after the collapse of the enemy's front line, the spearmen and swordsmen could engage to finish the battle (see the left of Fig. 1). As the Japanese army had long swords with the capacity to deal deadlier wounds by wielding them with both hands, the Korean soldiers lost their morale merely by seeing the glinting reflection of sunlight on the Japanese blades. Joseon suffered successive defeats and the capital fell in just twenty days. ${ }^{13}$

Following the victory of the Joseon and Ming allied forces in the second siege of Pyongyang, Joseon tried to adopt the tactics and martial arts of the Ming Dynasty. This resulted in a tactical doctrine known as the Zhejiang tactics. ${ }^{14}$ Key to this approach was the strategic combination of firearms and close combat weapons in battle, where firearms were used at distance, and close combat tactics at short range. ${ }^{15}$ Joseon's government learned how to develop the Zhejiang tactics from the Chinese general Qi Jiguang, who had included them in his book Jixiaoxinshu, which featured many detailed examples. Having obtained it, however, no-one in Joseon could correctly interpret it because the information in the book was both brand new and full of the jargon and colloquialisms native to Southern China in the mid-sixteenth century. ${ }^{16}$ Han Gyo (1556-1627) ${ }^{17}$, a military specialist of the Joseon Dynasty, undertook the task of interpreting the book and introducing Ming military martial arts to Joseon. He selected talented Joseon troops and taught them to fight under the direct supervision of instructors from the Ming military

${ }^{13}$ For more details about the Japanese invasions of Korea from 1592-1598 see Swope, A Dragon's Head and a Serpent's Tail.

${ }^{14}$ Named after the Zhejiang province, where the tactics were developed. See footnote 8.

15 This may sound similar to the aforementioned Japanese combination of close combat weapons and firearms. In Zhejiang tactics, however, there was a more diverse range of firearms and close combat weapons that were utilised, and the emphasis was put on the firearms which had a longer shooting range than Japanese arquebuses. In Jixiaoxinshu, General Qi Jiguang gave further detailed instructions in the use of small-group tactics, psychological warfare, and other "modern" techniques. Qi believed that by creating different types of small units and integrating them into larger companies, battalions, and armies, they could operate like ears, eyes, hands, and feet, thus constituting a whole military "body." He also stressed using different weapons together and favoured utilising different tactics depending upon terrain, skills, and weaponry. Swope, A Dragon's Head and Serpent's Tail, p. 19.

16 King Seonjo (r.1567-1608), who was known for his eruditeness, confessed "I have read many difficult books concerning all kinds of subjects, but I have never seen a book like Jixiaoxinshu that I cannot understand." The Revised Annals of King Seonjo, February 1, 1594.

${ }^{17} \mathrm{Han}$ Gyo was a Confucian officer who, as well as military tactics, also specialised in various studies such as astrology and geography. During the Japanese invasions of 1592-1598, he took on the responsibility for compiling the Muyejebo. He also compiled the Yeongbyeong Silgi (Practical Guide to Military Training). 
forces stationed in Joseon, and gleaned detailed embodied knowledge of these martial arts from the experts themselves.

Over time, Joseon became adept in comprehensively evaluating the skill level of Ming soldiers' martial arts. They were soon able to assess the differences in technique among the various Ming military camps and the martial skills of Ming instructors. After such efforts, the first close combat martial arts manual, the Muyejebo, was compiled in 1598. The fact that it took six years to compile the Muyejebo was due to the continuing war, but also indicates that the introduction of these martial arts was quite difficult. The Muyejebo focuses on enhancing the Mandarin Duck Formation, which consisted of twelve soldiers with various close combat weapons and was used throughout the Joseon military, by including six martial arts relating to the use of shields, thorny spears, long spears, tridents, staffs, and long sabres. It is also complete with detailed charts that are missing in Chinese fight books, such as Jixiaoxinshu and Wubeizhi.

After the Imjin War, new discussions began pertaining to the continued implementation of the Zhejiang tactics. It was also shown that the use of arquebuses by infantry was not always beneficial to the supporting cavalry. Furthermore, Korean military strategists could now gauge the skill level of martial arts practiced by Chinese soldiers from their own experiences of employing various martial arts during the Imjin War. As the threat of Jurchen attacks from the north increased, however, Joseon needed new martial arts which could cope with the all-mounted force used by the Jurchen. ${ }^{18}$ It was therefore necessary to supplement the tactics of Jixiaoxinshu, which focuses on the tactical use of infantry and their martial arts against Japanese pirates. When engaged in a battle against the Jurchen, it was determined that the arquebusiers generally would engage first, at range, before being supported by spearmen and swordsmen in melee against the approaching cavalry. In order to do this more effectively, spearmen and swordsmen were now trained in how to shoot arquebuses, and the arquebusiers learned sword fighting techniques for close combat. ${ }^{19}$ In addition, it was advantageous to battle with the same cavalry tactics.

To better deal with the Jurchen cavalry, the long spears wielded by soldiers in the third and fourth rows of the Mandarin Duck Formation were replaced with dagger staffs (see the right of Fig. 1). A dagger staff is just half the size of the long spear and very effective for both stabbing and striking. The long spear is not effective against heavily armoured cavalry due to its long length, which is easily broken by the cavalry's impact. The dagger staff was thus judged to be more effective in finishing the fight: soldiers wielding this weapon would strike the enemy horseman as the soldiers equipped with the thorny spear simultaneously interrupted the horseman's assault and the men armed with shields cut the horse's legs to cause the enemy to fall from his horse (see the middle of Fig. 1). Joseon forces armed with flails, blue dragon moon sabres, double sabres, hooked spears, and other weapons also required a systematic manual. To this end the Muyejebo Beonyeok

${ }^{18}$ Choi, Sibpalki, p. 87.

19 The Annals of King Seonjo, July 24, 1600. 
Sokjï ${ }^{20}$ was compiled in 1610, in which was included techniques for gwonbeop (quanfa in Chinese, bare handed fighting), blue dragon moon sabre, dagger staff [hooked spear], and waegeom. Gwonbeop was considered the fundamental basis for learning martial arts, but was not included in the Muyejebo due to the priority of weapon techniques required by the Mandarin Duck Formation during the Imjin War. The waegeom appears in the Muyejobo Beonyeok Sokjip in the form of training for single combat with the long sabre, which is an application of long sabre in the Muyejebo.

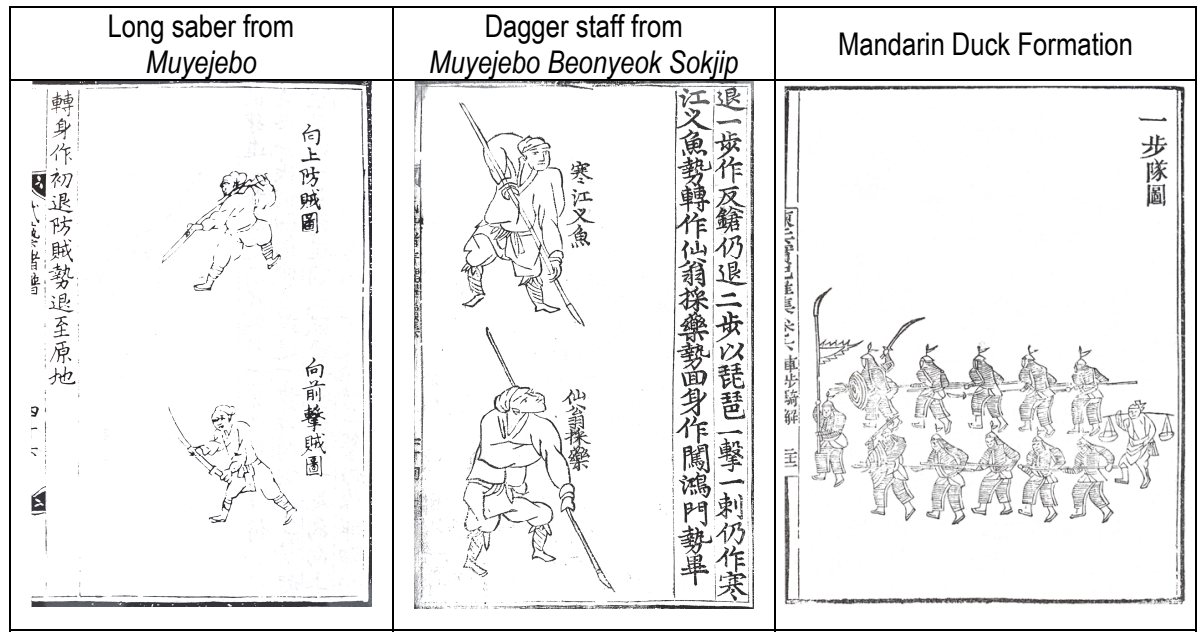

Figure 1: Muyejebo, Muyejebo Beonyeok Sokjip and the Mandarin Duck Formation

From then on the techniques of the Muyejebo and Muyejebo Beonyeok Sokjizp remained the core of Joseon's martial arts but other martial arts were adopted by military. The Muyesinbo, compiled in 1759, shows that various martial arts involving long bamboo spears, flag spears, yedos ${ }^{21}$, waegeoms, sword combat, admiral's swords, Silla swords (bongukgeom), double-handed sabres, moon sabres, pole sabres, gwonbeop, and staffs were added, and became known as sibpalki.22 Sibpalki literally means "eighteen arts", which

20 The Sokjïp also contains maps of Japan and information about Japanese ships and swords, as well as other general information about the country, which show Joseon was still alert to the threat posed by Japan. Na, Roh, Yang, and Choi, Joseon Junggi Muyeseo. pp. 6-7.

21 Yedo, also known as Joseon Sebeop (Chaoxian shifa in Chinese), was recorded in Wubeizhi. According to Mao Yuanyi, the compiler of Wubeizhi, there was no double-edged swordsmanship left in MingChina but because he found this swordsmanship in Joseon he included it to his Wubeizhi. Joseon sebeop was renamed as yedo and the double-edged sword was replaced by the single-edged sword in the Muyedobotongii. See Fig. 4 and footnote 9.

22 Crown Prince Sado (1735-1762), who was the second son of King Yeongjo (r.1724-1776), compiled Muyesinbo. Sado's attempts to foster new military nobilities and to standardise martial arts systems led him to compile Muyesinbo. Bae, Jeongjo ui Gunsa Jeongchaek, p. 342. 
refers to the entire martial arts described in the Muyejebo and Muyesinbo,: it is the official name for the Joseon martial arts system and has been used since 1759 .

In the autumn of 1789, King Jeongjo commissioned Park Je-ga, Lee Deok-mu, and Baek Dong-su to make a book of martial arts. In April 1790, less than a year later, the four volumes of the Muyedobotongii was completed. King Jeongjo bestowed his own preface and the title, Muyedobotongii, which means a book explaining the secrets of martial arts using drawings and charts. All of the work, including planning, writing, editing, engraving, printing, and publishing was done within a year. The reason why the large-scale compilation project could be completed in so short a time was because of the existence of the previously compiled fight books. The Muyedobotongii contains twenty-four arts in total, incorporating six cavalry arts to the other eighteen martial arts of the Muyesinbo.

The authors of the Muyedobotongii substantially raised the standards involved with delivering a vast amount of martial arts information in a systematic way. The Muyedobotongi includes the contents of the previous martial arts texts, adopting data classification methods used to compile contemporary law books and marking the contents with the labels "original", "addition", and "note". Although its primary function was to document the changes in martial arts, this system now enables us to trace the process of martial arts development. The content taken from the Muyejebo was marked "original", and the content added by the Muyesinbo and the Muyedobotongji were indicated as "addition" and "note". "Note" especially refers to a comment added during the compilation of the Muyedobotongii. The Muyedobotongi is thus the archaeological record of martial arts over a period of two centuries spanning from 1598 to 1790 (see Fig. 2). ${ }^{23}$

23 Park, Muyedobotongii Jubae. 


\begin{tabular}{|c|c|c|c|c|c|}
\hline $\begin{array}{c}\text { Muyejebo } \\
1598\end{array}$ & $\begin{array}{c}\text { Muyejebo } \\
\text { Beonyeok Sokjip } \\
1610\end{array}$ & $\begin{array}{c}\text { Muyesinbo }^{24} \\
1759\end{array}$ & \multicolumn{3}{|c|}{$\begin{array}{c}\text { Muyedobotongji }{ }^{25} \\
1790\end{array}$} \\
\hline Original & {$[-]^{26}$} & Original, Addition & \multicolumn{3}{|c|}{ Addition, Notes } \\
\hline $\begin{array}{l}\text { Long spear, } \\
\text { trident, thorny } \\
\text { spear }\end{array}$ & & $\begin{array}{l}\text { Long spear, long } \\
\text { bamboo spear, flag } \\
\text { spear, trident, } \\
\text { thorny spear }\end{array}$ & $\begin{array}{l}\text { Book } \\
1\end{array}$ & Stabbing & $\begin{array}{l}\text { Long spear, long } \\
\text { bamboo spear, flag } \\
\text { spear, trident, thorny } \\
\text { spear, spear on } \\
\text { horse }\end{array}$ \\
\hline Long sabre & Waegeom & $\begin{array}{l}\text { Double-handed } \\
\text { sabre, yedo, } \\
\text { waegeom, sword } \\
\text { combat }\end{array}$ & $\begin{array}{l}\text { Book } \\
2\end{array}$ & Cutting & $\begin{array}{l}\text { Double-handed sabre, } \\
\text { yedo, waegeom, } \\
\text { sword combat }\end{array}$ \\
\hline Shield & $\begin{array}{l}\text { Blue dragon moon } \\
\text { sabre, } \\
\text { dagger staff[hook } \\
\text { spear] }\end{array}$ & $\begin{array}{l}\text { Admiral's sword, } \\
\text { Silla sword, double } \\
\text { swords, moon } \\
\text { sabre, pole sabre, } \\
\text { shield }\end{array}$ & $\begin{array}{l}\text { Book } \\
3\end{array}$ & Cutting & $\begin{array}{l}\text { Admiral's sword, Silla } \\
\text { sword, double swords, } \\
\text { moon sabre, pole } \\
\text { sabre, shield double } \\
\text { swords on horse, } \\
\text { moon sabre on } \\
\text { horse }\end{array}$ \\
\hline Staff & Gwonbeop & $\begin{array}{l}\text { Gwonbeop, staff, } \\
\text { flail }\end{array}$ & $\begin{array}{l}\text { Book } \\
4\end{array}$ & Striking & $\begin{array}{l}\text { Gwonbeop, staff, flail, } \\
\text { flail on horse, polo, } \\
\text { acrobat on horse }\end{array}$ \\
\hline
\end{tabular}

Figure 2: A Comparison table of Muyejebo, Muyejebo Beonyeok Sokjip and the Muyedobotongji. Bold style characters indicate martial arts added in the Muyedobotongii.

Fig. 2 shows the differences present in fight book content from the Joseon Dynasty. There is an overall increase in the number of martial arts described, and the increase in attention given to sword arts is particularly remarkable. The completion of the martial arts required for the infantry was achieved in the Muyesinbo. Of the eighteen martial arts

24 Muyesinbo, which is not extant, was compiled by Crown Prince Sado in 1759. Its contents can be reconstructed via a comparison to other fight books like Muyejebo, Muyejebo Beonyeok Sokjip and Muyedobotongij.

25 An overview of military affairs, profiles of Qi Jiguang and Mao Yuanyi, questions and answered on martial arts techniques, and a bibliography are all included before the main sections of the Muyedobotognji. This table highlights the changing nature of martial arts so the other contents are not listed herein.

26 The title of Muyejebo Beonyeok Sokjip was not explicitly cited in the Muyedobotongii although the contents of Sokjip were interconnected to the Muyedobotongij. 
of the Muyesinbo, ten were related to swordsmanship. The increase in sword arts was a reflection of the situation on the battlefield in the late Joseon Dynasty. From the sixteenth century onward, the arquebus became the principal battlefield weapon. As the performance of the arquebus improved with advances in technology, the role of spearmen and swordsmen to cover the arquebusiers diminished. Instead, the arquebusier now carried his own sword, which he could use should he find himself in melee. As part of this process personal fencing skills became more and more important. The compilation of fight books was heavily influenced by these circumstances. Evidence for this can be seen in the fact that there was only one sword technique in each fight book of the Muyejebo and Muyejebo Beonyeok Sokjizp - such as long sabre and waegeom - but the second and third volumes of the Muyedobotongii were increasingly devoted to swordsmanship, which accounts for more than half of the total content. (See the Muyedobotongii column in Fig. 2).

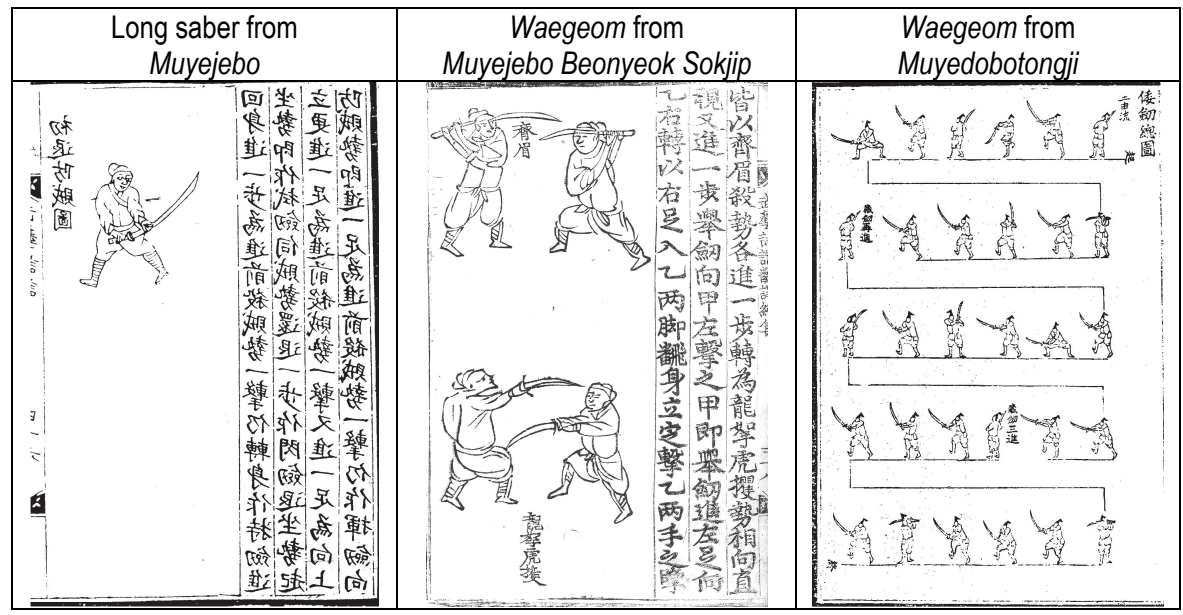

Figure 3: Swordsmanship in Muyejebo, Muyejebo Beonyeok Sokjip, and the Muyedobotongii

Much of Joseon's swordsmanship is related to the Japanese model. The long sabre of the Muyejebo originated from Japanese kage-ryu swordsmanship and passed from China to Joseon (see the left of Fig. 3). ${ }^{27}$ The waegeom depiction in the Muyejebo Beonyeok Sokjip is a form of single combat training created by Joseon and based on the long sabre techniques of the Muyejebo (see the middle of Fig. 3). The waegeom in the Muyesinbo, although it shares the same name as the waegeom in the Muyejebo Beonyeok Sokjiz, uses a completely different technique. The waegeom in the Muyesinbo (and also in the Muyedobtongiz) is a form of Japanese swordsmanship, itself composed of techniques from four different schools, which was acquired by spying on Japanese settlements in Joseon that was undertaken by Kim Chegeon, a Joseon military officer. ${ }^{28}$ The sword combat form in the Muyesinbo is a single

\footnotetext{
${ }^{27}$ Choi, Japanese Swordsmanship. pp. 30-1.

${ }^{28}$ Ibid, pp. 32-3.
} 
combat training method derived from the four different styles of waegeom acquired by Kim Che-geon. Most of these methods were included in the Muyedobotongji.

Even though the long sabre of the Muyejebo was included in the Muyedobotongji, it differed from the original method of use. The long sabre wielded in the Muyejebo was $140 \mathrm{~cm}$ long, but it was no longer in use by the eighteenth century, having been replaced by a hwando, or a standard waist sabre (about $90 \mathrm{~cm}$ long), for practice. Although the sabre's length was reduced, the technique's name remained ssangsudo, or double-handed sabre, in the sense of a sabre originally requiring both hands due to its length. ${ }^{29}$ The blue dragon moon sabre in the Muyejebo Beonyeok Sokjip was included in the Muyedobotongji, but here the name was simplified to moon sabre, and though the overall flow of turo (form, kata, or poomsae) remained the same, the number of postures (dynamics) included increased from eleven to nineteen. ${ }^{30}$

The long spear combat in the Muyedobotongii is virtually the same as in the Muyejebo. The total number of long spear postures in Jixiaoxinshu is twenty-four. The first form created by Han Gyo, however, uses only twelve postures as when he learned the long spear techniques from Ming instructors they themselves did not know all twenty-four. Later, Han Gyo created another long spear form using the other twelve postures. As a result, the Muyejebo had two different long spear forms. These two forms were also included in the Muyedobotongji, displayed in the same way as in the Muyejebo. ${ }^{31}$

The Muyedobotongii also contains a record of the traditional Joseon swordsmanship, such as it was practiced with the Silla sword (bongukgeom) and yedo (Joseon sebeop). Remarkably, the yedo chapter is composed of two different styles of swordsmanship. The first one is the Korean version of Joseon sebeop (Joseon Sword Method), which was originally recorded in the Wubeizhi as double-edged swordsmanship (see the left of Fig. 4). The sword, however, was replaced by the sabre in the Muyedobotongji, which means it was practiced as specific sabre techniques in Joseon (see the middle of Fig. 4). The second style is a sequential form of Joseon sebeop (the original Joseon sebeop was a collection of individual techniques not designed as a sequential form). When compiling the Muyedobotongij, there was a sequential form of Joseon sebeop practiced called yedo. The authors of the Muyedobtongii included the sequential form at the end of the yedo chapter (see the right of Fig. 4).

${ }^{29}$ Due to the length of the long sabre, one would wield the sword by holding the part around the babaki (donghoin in Korean, the metal "collar" next to the guard) or the blade near the guard. See the left of Figure 3.

${ }^{30}$ Choi, Historical Backeground of the Muyedobotongij, pp. 64-6

31 See the long spear chapters in both the Muyejebo and Muyedobotongii in Park, Lee, Wonbon Muyedobotongii. 


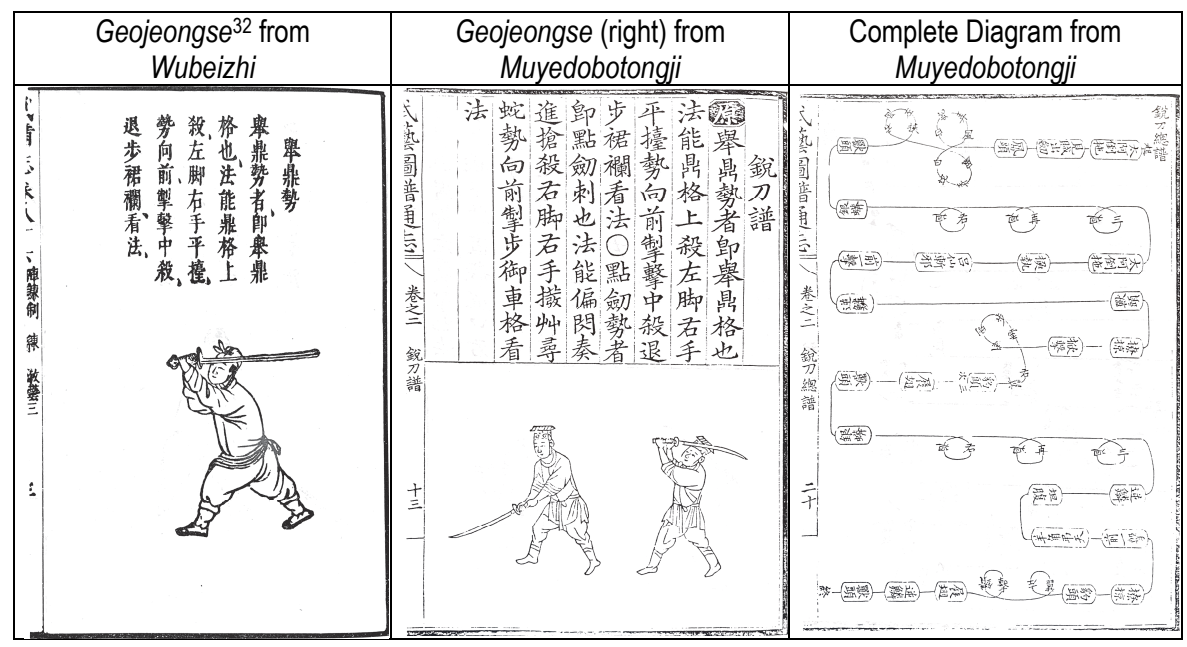

Figure 4: The changes in Joseon sebeop (yedo) from Wubeizhi to Muyedobotongii

It is worth noting that the role of the cavalry decreased relative to the rising reliance on the arquebus as the primary weapon. In the late eighteenth century, however, mounted martial arts began to draw increasing attention again as tactics that incorporated light cavalry were proven to be quite effective. This was because the speed and agility of light cavalry proved to be especially powerful when they were tasked with harassing the enemy. This change was reflected in the Muyedobotongii, which includes combat with double swords on horseback (masang ssanggeom), moon sabre on horseback (masang woldo), flail on horseback (masang pyeongon), gyeokgu (a form of polo), and acrobatics on horseback (masangjae). ${ }^{33}$

There are also changes to the unarmed gwonbeop fighting. Both gwonbeops of the Muyejebo Beonyeok Sokjizp and Muyedobotongii use dynamics from Jixiaoxinshu as the basic raw material for developing their forms but they differ in terms of how both the composition and the number of postures were incorporated. This significant variation causes them to be seen as completely different gwonbeops. The gwonbeop of the Muyedobotongii was practiced by two practitioners who would start and finish together as a duo, whereas the gwonbeop of the Muyejebo Beonyeok Sokjip was a solo training form. ${ }^{34}$

As seen above, the martial arts in the Muyedobotongii were the result of a process of evolution extending over 200 years from 1598 to 1790 . When these fight books were compiled Joseon did not revere the old martial arts as ultimate and unchangeable authorities, but instead made martial arts suitable for the current situation by creating, modifying, or adding new ones as needed. There were many factors contributing to the

\footnotetext{
32 Geojeongse meaning "dynamics of lifting the cauldron".

33 See chapters on equestrian techniques in the Muyedobotongji.

${ }^{34}$ Choi, Taekwondo Jeonsa, pp. 66-9.
} 
evolution of martial arts. Martial arts evolution emerges from the necessity for newer and more effective military tactics. Indeed, martial arts themselves arose and evolved out of the matrix of actual, real training. The differences between the military camps in the late Joseon period was one of the reasons behind the compilation of a more unified and comprehensive manual: the Muyedobotongij. As shown by the example of bongukgeom and yedo, new martial arts were created based on old materials. The Muyedobotongji was compiled in 1790 in order to produce a synthesis of contemporary martial arts and to further the establishment and dissemination of standard martial arts.

\section{TRANSMISSION AND RECONSTRUCTION OF MARTIAL ARTS IN THE MUYEDOBOTONGJI}

The history of the Muyedobotongii does not end with its creation, and the events that took place after the compilation also require some exploration. King Jeongjo hoped to reform the current military system by completing the Muydobotongii project, which would allow for the further standardisation of training methods. However, this project was discontinued as a consequence of King Jeongjo's sudden death in 1800. In the following era, Joseon struggled with political complications involving the royal family, ultimately creating the conditions for the Japanese occupation. During this period the military system of Joseon gradually collapsed. Sibpalki also lost its prominence due to a transformation to modernity in the late nineteenth and early twentieth centuries. ${ }^{35} \mathrm{In}$ 1907, Joseon's military troops were dismissed by the Japanese and sibpalki was no longer considered the official martial arts of Joseon.

As the Japanese colonial era continued, sibpalki and the Muyedobotongji almost disappeared from people's memories. It was only occasionally, and briefly, mentioned in newspaper or magazine articles. Even after the liberation from Japanese colonial rule in 1945 sibpalki remained in obscurity. It was only in the 1970s that the Muyedobotongii resurfaced in public. Kim Gwang-suk, who had learned the Muyedobotongii martial arts from Yoon Myeongdeok, opened his martial arts dojang in 1970, gave it the name "Sibpalki", and started to teach people and share information about sibpalki and the Muyedobotongij. In 1981 he established the Korea Sibpalki Association to promote sibpalki and classical martial arts in Korea. From 1987 he also devoted himself to theorising and publishing books on martial arts including Practical Analysis of Muyedodobotongii (1987), Secrets of Muyedobotongii Gwonbeop (1992), Bongukgeom: Korean Swordsmanship (1995), and Textbook of Korean Spear and

\footnotetext{
35 According to the 1808 edition of Mangi Yoram, or the Handbook of State Affairs, the Military Training Command stationed in Seoul had 8,239 muskets, 206 cavalry rifles, 119 bronze cannons, 17 crouching tiger cannons, 10 circular cannons, 2 red-haired barbarian cannons, 65 Frankish culverin cannons including 15 pieces of No.4 type and 50 pieces of No.5 type, 335 baby cannons, 11 bronze rifles, 153 triple-barrel rifles and 10,558 bows and many catapults. There were also close combat weapons listed, mostly sabres and flails, including 7,219 waist sabers (bwando), 2,774 flails, 30 moon sabers, and 26 pole sabers. Choi, Sibpalki, pp. 165-6.
} 
Staff Techniques (2003). Thanks to such efforts sibpalki was recognised in 2019 as one of the "Traditional Joseon Military Martial Arts". ${ }^{36}$

The major obstacle to sibpalki becoming officially recognised as a Korean martial art, and the reason why it took so long, was the social prejudice concerning just what Korean martial arts were supposed to be. Kim Gwang-suk had already brought the Muyedobotongii and sibpalki into the public eye in the 1970s, but at the time sibpalki was considered a branch of Chinese martial arts: Kim interacted with Chinese martial artists, with whom he exchanged martial arts knowledge, and adopted a modern Chinese training system to run his dojang. Teaching sibpalki in the late twentieth century was hard as it required both an adequate supply of proper training gear, including weapons, and ample space in which to wield them. Moreover, because of the disproportionate popularity and appeal of unarmed martial arts (kung fu), bare-handed training forms were in high demand. Sibpalki, as classical martial arts, have only a single gwonbeop form. To meet the demand Kim added some Chinese gwonbeop forms to his curriculum after revising and adapting them into the sibpalki style. After the establishment of the Korea Sibpalki Association, Chinese martial artists who followed Kim Gwang-suk also joined and received the dan certificate from the organisation. Due to these factors Kim Gwang-suk's sibpalki was misunderstood and perceived as Chinese and not Korean martial arts.

Years later in 1990, Lim Dong-gyu claimed that he was the one who first reconstructed the martial arts of the Muyedobotongji. Lim chanced across a copy of the Muyedobotongiz while he was in prison and began to reconstruct the movements by imitating the postures in the drawings. After his release, he realised that Kim Gwang-suk was already teaching it as the legitimate successor, both to the art and to Yoon Myeong-deok. ${ }^{37}$ Lim Dong-gyu, who already called his martial arts isipsa-ban muye (twenty-four skills), established the Isipsa-ban Martial Arts Association and began to promote and disseminate it. The two styles were so different that it was hard to merge with Kim Gwang-suk's sibpalki.

\footnotetext{
36 Sibpalki, isipsa-ban and masang muye (equestrian arts), which were all based on the Muyedobotongji, were registered as Seoul's Intangible Cultural Property No. 51 under the name of "Traditional Military Arts" on 24 February, 2019.

${ }^{37}$ I use the term "legitimate" here in the sense that Kim has fair and acceptable reasons to be considered the successor of the art of the Muyedobotongji. Kim learned sibpalki from his teacher, Yoon Myeong-deok, and was the first to publicly reveal the martial arts system of the Muyedobotongji. Before his revelation there was nobody who showed the whole martial arts system of the Muyedobotongii both in theory and practice. He also shared classical martial arts theory he learned from Yoon with the public. Attempts at partial reconstruction have also been made by kendoka or taekwondo practitioners; their reconstructions, however, focus on a certain art, not covering the full range of the book, and are thus incomplete. Kim's teaching corresponds to the ancient martial arts curriculum theory present in the Muyedobotongi and other sources, such as Jixiaoxinshu, Wubeizhi, Dandaofaxuan, Shaolin Gunfa Canzong. Above all things, as a living tradition he clearly showed the errors of the Muyedobotongi itself as a text which is often not perceived by modern practitioners and researchers.
} 
Lim Dong-gyu, who attempted to reconstruct martial arts based solely on scripted information in prison, relied entirely on his own imagination and interpretation. It can also be said that in his confinement his attempts at reconstruction work could not be challenged by anyone on the outside. After leaving prison, he was able to refine his isipsaban martial arts by studying, adopting, and adapting other martial arts.

The reconstruction work of Lim Dong-gyu, reveals several examples of trial and error. First is the interpretation of the size of the weapons. To restore the weapons of the Muyedobotongji, Lim Dong-gyu converted the specifications mentioned in the text by translating Yeongjo cheok into the metric system: 1 cheok is approximately $31 \mathrm{~cm}$. In this case, the total lengths of the sword and the spear become $133 \mathrm{~cm}$ and $465 \mathrm{~cm}$ long, respectively. ${ }^{38}$ In addition, he criticised the length of the swords used by Kim Gwang-suk for being too short and failing to match the original specifications. In response, Kim Gwang-suk argued that the Jucheok, which is approximately $21 \mathrm{~cm}$ to 1 cheok, should be applied as the proper measure for the conversion of the Muyedobotongi swords' length. This dimension was in accord with his own real-world martial arts experience. Recent research supports Kim's assertion. ${ }^{39}$

There is also some debate over the name of the official martial arts of the late Joseon Dynasty. When Kim learned martial arts from his teacher, Yoon Myeong-deok, Yoon emphasised the name "sibpalki" and the Muyedobotongji. After the Korean War ended, Kim could actually see the Muyedobotongii for himself, which confirmed what he had learned of it. ${ }^{40}$ On the other hand, Lim Dong-gyu insisted that isipsa-ban muye was the right name. Lim Dong-gyu's claim is wrong because the term sibpalki was in actual use as the official name of the martial art in the late Joseon Dynasty, found in official government records as well as in private collections and civilian records. ${ }^{41}$

Furthermore, in terms of techniques, Lim Dong-gyu's reconstruction is found to be incompatible with the principles of classical martial arts. Since it is primarily focused on superficially reproducing the movements depicted in the drawings of the Muyedobotongji, the errors which crept into the process of printing the Muyedobotongii are unfortunately repeated in his reconstruction. Moreover, the methodology itself of reconstructing the techniques by simply mimicking the shapes of the figures in the drawings is widely

\footnotetext{
38 Such knowledge was probably so common that the authors of the Muyedobotongji and people in the eighteenth century did not need to specify which scales to apply. Today, however, to reconstruct the weapons used in Joseon, we need to decide a right conversion scale either Yeongjo cheok (1 cheock $\approx 31 \mathrm{~cm})$ or Jucheok $(1 \mathrm{cheok} \approx 21 \mathrm{~cm})$.

${ }^{39}$ National Folk Museum of Korea, Joseon Hugi Mugi.

40 The life of Yoon Myeong-deok, who was Kim Gwang-suk's teacher and a distant relative, is not well known. According to Kim's memory he had been chased by the Japanese police during the Japanese colonial period. During the Korean War, after the liberation from Japanese rule, Kim learned sibpalki and other traditional knowledge like medicine, meditation, and qigong from Yoon. Shin, Mudeok, pp. 465-475.
}

${ }^{41}$ Park, Joseon Hugi Gongsik, pp. 55-65. 
considered questionable in the modern martial arts circle of Korea. For example, when reconstructing the "five flowers winding body postures" in the double swords section, Lim simply interprets the text literally and places the sword under the armpit and spins three times to the right while keeping the upper body fixed. In the end, it becomes an unnatural movement without any relevance to actual sword techniques, much like a mannequin spinning around. In contrast, Kim Gwang-suk shows the meaning of the movements by using both swords to cut diagonally and simultaneously block while also turning around with proper footwork. ${ }^{42}$

There is a key difference between transmission and reconstruction. The system of techniques, that in this case is the object of transmission, has evolved according to real circumstances such as military tactics, lifestyle, culture, and the contemporary social context. However, if a reconstruction happens at a time when the transmission of a martial art itself is extinct, a new tradition may be created by incorporating old fragments (which are often summoned from historical records) into a living art. In this process, reconstruction has been done without being limited to the inertia of the tradition. It is also common to see reverse engineering of traditionality by adding external decorations, such as traditional costumes, and requisites into the reconstruction process. In this respect, reproducibility tends to be stronger in reconstruction than in transmission because transmission is the result of adjustment over time from the perspective of evolution..$^{43}$

Today, the transmission and reconstruction of the Muyedobotongii are becoming similar in appearance. All techniques are subject to the perceptions of those who live at the time. Imitation will inevitably occur in situations where video is shared on a daily basis. If the apparent difference between transmission and reconstruction seems to be disappearing, how can we tell the difference between the two? The consistency of classical martial arts theory and practice can be considered as a factor that distinguishes the two. The body of classical martial arts knowledge was established according to the East Asian epistemological basis. The fact that East Asian fight books share a language that explains theory and practice - despite the difference in time and space and the fact that reconstructed martial arts (in Korea) have not yet reached this epistemological basis shows that the reconstruction process still has a long way to go.

The degree to which classical martial arts theory and practice in reconstruction is understood is still at a rudimentary level. When reconstruction reaches the stage of

\footnotetext{
${ }^{42}$ Kim Gwang-suk's techniques have been widely spread since 1987 and most reconstructed martial arts groups of the Muyedobotongji today follow his style with only small differences.

43 The birth of the Cultural Properties Protection Law in 1962 in Korea shifted the focus from the inheritors as producer of certain arts to the products they produce. As a result, in order to succeed in the preservation and development of national culture there emerged a new social field surrounding new interpretations of traditional cultures, legitimate rules and system to preserve them, and the power struggle between the legal subject and the legal object. Jung, Hanguk Mubyeong Munhwajae, pp. 133-7.
} 
codifying martial arts terminologies, meanings, and theories used in transmission, however - in other words, when classical martial arts knowledge is widely shared - then both transmission and reconstruction will inevitably meet. In the sense that reconstruction eventually contains the features of transmission, however, questions still remain regarding how we can differentiate between transmission and reconstruction.

\section{THE INVENTED MARTIAL ARTS}

In the 1980s Kim Gwang-suk's efforts drew people's attention to the Muyedobotongij. His efforts were connected to the contemporary social circumstances facing those who had embraced the challenge of restoring national self-consciousness and were attempting to figure out how to successfully develop national traditions.

During the lifespan of the Korean Empire (1897-1910) both the Korean police and military were trained in imported kendo. Subsequently, judo was introduced during the Japanese colonial era (1910-1945). Both kendo and judo became part of the physical education curriculum in elementary and middle schools, and also proved popular nationwide as club sports in the early twentieth century. The syllabus of physical education prescribes precisely how kendo and judo were intended to transform Korean people into good loyal Japanese subjects. ${ }^{44}$ The Japanese colonial era was also a period of modernisation. In addition to sports like football, basketball, baseball, and tennis, Western cultural approaches to the body were also introduced. In the meantime there was scant awareness or sentiment that Korean classical martial arts also needed to be passed on to Koreans.

It was only after liberation that Koreans became aware of the need to preserve and manage national culture, especially given the increasing influence of foreign cultures. In 1962, the Cultural Property Protection Law was created to preserve and protect tangible and intangible cultural properties at a national level. The intangible cultural property system was established on an ideological basis to preserve the "archetype of national culture". The fact that intangible cultural properties have become the subject of national management presupposes the idea that the form of cultural art can be separated from its producers. ${ }^{45}$

The transformation of taekkyeon from folk play to a traditional martial art shows how embodied culture of the past has secured the status of a tradition and received official recognition. ${ }^{46}$ Taekkyeon, which was popular in and around Seoul as a kicking game until

${ }^{44}$ Lee, Geundae Sinche Munbwa, p. 54.
45 Jung, Hanguk Mubyeong Mnbwajae Jedo.
46 Taekkeyeon is claimed as a bare-handed martial art with thousands of years of history in Korea.
An analysis based on historical records concerning taekkyeon indicates that its origin is highly likely
to be connected to Chinese quanfa, which was introduced to Korea during the Japanese invasions
of Korea between $1592-1598$. Quanfa was possibly altered to the playful taekkeyeon after it spread to
civilian society from the military. Choi, Taekwondo Jeonsa, pp. 66-9. For the details of taekkeyeon in the 
the end of the Korean Empire, was almost entirely forgotten during the Japanese colonial era. Taekkyeon returned to the spotlight since it featured in the reverse- engineered history of taekwondo. ${ }^{47}$ Taekkyeon was later designated an intangible cultural property through the efforts of Shin Han-seung (1928-1987) in 1983, consolidating its position as traditional martial art. The taekkyeon that Shin Han-seung registered as an intangible cultural property, however, was a modernised form with elements taken from other modern martial arts with which Shin Han-seung was familiar. His technical system, which he invented, became the "cultural archetype" of taekekyeon. In being recognised as a national intangible heritage, the personal subjectivity of the taekeyyeon trainee disappeared and, as a traditional Korean martial art, the position of taekkyeon became more and more consolidated. The modern, reconstructed taekkyeon became an archetype and took over the hegemony of succession and preservation. ${ }^{48}$ As it was registered as a world intangible cultural heritage in 2017, taekkyeon began to solidify its position from a traditional Korean martial art into an international one.

On the other hand, taekkyeon's registration as an intangible cultural property acted to formally traditionalise taekkyeon while also strengthening the dominant image of barehanded fighting in classical martial arts during the late Joseon period. Although martial arts gained social recognition by being incorporated into one of the cultural traditions, the downside of this was that it distorted and diminished the perception of the seminal position of armed combat techniques. In classical martial arts weapon skills were the core, but registering a kicking game as a traditional martial art helped to distort the very perception of tradition.

The example of taekekyeon's registration as a world intangible cultural heritage provides interesting points of contrast compared to sibpalki. Both have similarities in the process of passing down their tradition via a system of rightful succession; Yoon Myeong-deok and Kim Gwang-suk in sibpalki and Song Deok-gi and Shin Han-seung (and Song Deokgi) in taekkyeon. ${ }^{49}$ Both became significant as a result of external influences during the process of modernisation from Chinese and Japanese martial arts. As such, questions surround the fact that taekeyeon is registered as an intangible cultural property whereas sibpalki is not.

As Kim Gwang-suk's biography shows, the sibpalki he taught was different to what he learned from Yoon Myung-deok. In the process of sibpalki's transmission, as a military martial art, through Yoon Myung-deok, it had already turned into a civilian art, and it is possible that many of the original characteristics of sibpalki were lost due to the specific impact of the Korean War. In addition, the process of teaching sibpalki to the public

late nineteenth century see Culin, Korean games: with notes on the corresponding games of China and Japan (University of Pennsylvania, 1895).

${ }^{47} \mathrm{Kim}$, Taekwondo Cheolhak, pp. 71-7.

48 Lee, Muye Wonbyeong-ui Jedobwa.

${ }^{49}$ See Shin, Mudeok; Park Jong-gwan, Jeontong Musul Taekkyeon; Lee, Mubyeong Munbwajae Taekkyun. 
required the ability to adapt to the expectations of the audience. ${ }^{50}$ This sequence of steps is exactly the same as those faced by Shin Han-seung's learning of taekkyeon and teaching it to the public. The process of reconstructing taekkyeon in order to register it as an intangible cultural property also overlaps with the process of modernising sibpalki.

The modernised sibpalki that Kim Gwang-suk conveyed is based on - but is not limited to - the Muyedobotongji. The way that Kim explains the functionalities of the human body and its movement using the logic of classical martial arts has not been verified by those who claim to have inherited any traditional martial arts, or any specific martial arts of the Muyedobotongij. It remains undecided, however, whether his martial arts could be officially recognised as a traditional martial art; as Eric Hobsbawm suggests, not everything in the past becomes a tradition. Tradition is created by today's needs. ${ }^{51}$

The debate over the past thirty years in the Korean martial arts community between advocates of transmission on one hand and reconstruction on the other has sparked a social interest in the concept of tradition. The reason why the boundary between transmission and reconstruction seems vague today is because it is difficult to define the characteristics of tradition. According to the Traditional Martial Arts Promotion Law, traditional martial arts are defined as systems of body conditioning, techniques, and combat application that are indigenously organised in Korea or originated from abroad but were creatively formalised and systemised in Korea, and recognised as having traditional and cultural values deserving of nationwide promotion. ${ }^{22}$ The problem is that this regulatory definition is ambiguous in reality. As indicated by the "Basic Plan for the Promotion of Traditional Martial Arts" (a specific implementation guideline of the Promotion Law), the definition of the Promotion Law pertains only to the origin and form of martial arts, but does not specify what traditional and cultural values actually entail.

The categorisation of transmission, reconstruction, creation, and foreign martial arts are also controversial. For example, taekwondo can also be classified as a tradition in that it has been a martial art for more than seventy years. In addition, it can be classified as a foreign martial art due to the fact that it comes from karate, and it can even be a created martial art in that the name taekwondo, its forms, and competition structures were all newly invented and introduced. Although the taekwondo community is not attempting to reconstruct the gwonbeop of the Muyedobotongiz in earnest, if they attempted to do this in the taekwondo way then it could conceivably qualify as a reconstructed martial art. This is a good example of the complexities involved first in deciding whether or not a martial art fits the official criteria, and then how to categorise it (as transmission, reconstruction,

\footnotetext{
50 See Kim, Gwonbeop Yogyeol (1992); Bongukgeom (1995); Joseon Cangbong Gyojeong (2003)

${ }^{51}$ Hobsbawm and Ranger, Tradition. pp. 1-2.

52 No.1 of Article 2 (definition) in the Traditional Martial Arts Promotion Law.
} 
creation, or foreign). ${ }^{53}$ The "Basic Plan for the Promotion of Traditional Martial Arts" also classifies martial arts by outward appearances into bare-handed techniques, weapons techniques, comprehensive techniques, and spiritual training. This kind of classification according to external forms results from ambiguities in reality. In this case (and contrary to the intent of the Promotion Law), the emphasis here seems to be put on the definition of martial arts rather than on the concept of "tradition". Furthermore, it is widely known that many of today's traditions originated only in the nineteenth century, but in reality the public tends to believe just what they want to believe, and the denial of unfavourable or bothersome facts only tends to reinforce such belief in "tradition". 54

Since Kim Gwang-suk published a modern version of the Muyedobotongij, it has been consumed in various forms across modern Korean society. After its introduction various new martial arts arose whose practitioners claimed that they were genuinely traditional. Most groups of new "traditional" martial arts use only a part of the Muyedobotongji. ${ }^{55}$ This approach yet undermines the purpose of classical martial arts. The Muyedobotongii follows the curriculum of classical martial arts, first practicing gwonbeop and then staff, and only after mastering staff should one learn how to fight with other weapons such as swords, spears, tridents, and double swords. However, most organisations that claim traditionality tend to skip the basics and practice swordsmanship without first explaining gwonbeop. This approach is stuck at an arbitrary level in that the method involved with learning gwonbeop, sword, spear, staff, moon sabre, and other weapons together form an organically interconnected and integral system. The modern practice of the Muyedobotongij does not equate to the simple reproduction of its individual martial arts. Real succession could not have been achieved by extracting only parts of the Muyedobotongi and mimicking movements without the crucial understanding of the embodied knowledge of classical martial arts.

Invented traditions can also be cultural re-creations. However, Eric Hobsbawm's theoretical discourse on "invented traditions" is here raised because de facto incumbent hegemony creates "tradition" in order to control the minds of the people. Today, those who lead the "traditional martial arts" community, as well as the authorities and citizens, should endlessly question the different illusions and possible projections. ${ }^{56}$ The decisive criterion for defining tradition is the fact that it was created through human action,

\footnotetext{
53 According to the Basic Plan for the Promotion of Traditional Martial Arts (2009), Taekwondo is currently categorised as a type of creation.

54 One of the common myths encountered in mass media, as well as in academic studies, is that there exist only three indigenous Korean martial arts: gukgung (Korean archery), ssireum (Korean wrestling), and taekkyeon (see Jeong, Jeontong Muye Taekkyeon, pp. 16-9). This argument does not seem to adequately consider the universality of cultures.

55 There are many individuals and organisations in association with Korean kumdo (kendo), Haidong (Haedong) kumdo, and Bongukgeom working on the reconstruction of the Muyedobotongji. They focus on swordsmanship in the Muyedobotongji. For an example see Li, Siljeon Uri Geumdo.

56 Go Food Writing.
} 
thought, and imagination, and has clearly passed from one generation to the next. Thus a person who accepts tradition does not have to call it a tradition because it is self-evident. ${ }^{57}$ At the time of the original publication of the Muyedobotongii, the eighteenth-century public did not revere their previous fighting arts as the archetypes of martial arts; they were only used as references for compiling the Muyedobotongji. Today, however, the Muyedobotongji reigns as an archetype of classical martial arts. From understanding the Muyedobotongij, we must go one step further and deconstruct it. To do this, it is necessary to look at the past not from the perspective of the mythical traditionalist, but that of the humanistic-oriented rationalist.

\section{CONCLUSION}

Instead of asking the initial question, "can we learn martial arts through books?", it would be more productive to rephrase it as "can the martial arts reconstructed through books be socially recognised as embodied knowledge (in Korea)?". As seen in the controversies between transmission and reconstruction, the answer will change depending on the social circumstances in which classical martial arts are cultivated and accepted.

The Muyedobotongii, which is based on East Asian martial arts traditions, shows how martial arts were produced, developed, and evolved in Korea while also adapting to social preferences and needs. The Imjin War was a turning point. Joseon started to devise a new martial arts system to cope with the changing military situation and even tried to incorporate Chinese and Japanese martial arts, when relevant and necessary, to improve Joseon's military system. From a contemporary Korean perspective, the Muyedobotongii was the result of the best selection of the best practices. In the Muyedobotongij, there was no nationalistic view of Korean martial arts (as is prevalent in the Korean martial arts world today) but a solely a pragmatic perspective.

There is of course a desire in the Muyedobotongiz to distinguish between Chinese, Japanese, and Korean martial arts, but it is very different from today's practice of dividing martial arts along national borders. The Muyedobotongi has no more meaning than revealing regional differences regarding the universality of East Asia. It is also a noteworthy insight that under the Joseon Dynasty the state was in charge of producing, transmitting, and recording the knowledge of martial arts, in contrast to the then common practice in Japan and China, where individuals or schools were responsible for producing martial arts records. ${ }^{58}$ Joseon placed martial arts management under control of the state and tried to unify the memory of the body of knowledge on an official statewide scale.

The process by which classical martial arts are reconstructed today is difficult to explain uniformly. Besides, it is impossible to verify whether both transmission and reconstruction convey the original form. As Korean examples show, however, the state's

57 Shils, Tradition, p. 25.

58 Even Qi Jiguang compiled his books based on his own initiative, which was to effectively train his military troops, whereas the Muyedobotongii was compiled by the order of the king. 
involvement in martial arts is unfolding differently. The Intangible Cultural Properties Protection Law and the Traditional Martial Arts Promotion Law try to keep the succession and development of martial arts under the influence of the state through legal and institutional mechanisms. The logic of the Intangible Cultural Property Protection Law, however, which presupposes and inherits the "archetypes" of martial arts, is missing the human element as the subject of "producing and practicing martial arts". The Traditional Martial Arts Promotion Law seems to be confused in its definition of "tradition" in a way that does not fit the original meaning, but rather functions to enhance the production of a novel "traditional martial art".

The debate on the traditionality of martial arts is somewhat related to anti-Japanese sentiment; the logic to arguments that the disappearance of Korean martial arts was due to Japanese oppression instils nostalgia for the ancient martial culture of Korea. Such arguments do not, however, match the historical facts. Unlike Japan, Korea did not have the opportunity to modernise classical martial arts when it fell under Japanese colonial rule. Kumdo (kendo) and judo, which arrived in Korea during the era of Japanese colonialism, became a model for modern Korean martial arts. A century ago, there was no opposition in Korean society arguing that Japanese kumdo and judo should not be practiced in Korea because they were not native Korean martial arts. In post-war Korean society after the liberation, the liquidation of the Japanese remnants took place at a national level. Kumdo and judo were turned into objects which were to be erased along with all other traces of Japanese influence. At the same time, the reconstruction and revival of traditional martial arts began to be supported and systematically improved by the national government.

Interest in traditional Korean martial arts also began to emerge in this new social atmosphere. However, the role models of Korean martial arts that had failed to modernise were, ironically, Japanese martial arts which Koreans experienced during the Japanese colonial era, and karate and hapkido that came into popularity around the time of the liberation. ${ }^{59}$ Modern Korean martial arts were created by imitating modern Japanese martial arts, yet at the same time, anti-Japanese sentiment became the driving force behind the Korean transformation of Japanese martial arts. There is a contradiction among the various modern Korean martial arts in that both the imitation and scathing attack of Japanese martial arts occurs simultaneously.

As we can see from the debate surrounding the Muyedobotongii, the way of looking at tradition perpetually mutates. In the process of modernisation, many traditional cultures first disappeared and were later recreated. If foreign martial arts took their place before subjective transmission, then traditional martial arts were inevitably distorted through the prism of those foreign martial arts. And as we see from the example of taekkyeon, when

\footnotetext{
${ }^{59}$ Hapkido, one of the most popular Korean martial arts nowadays, is evolved from Daitoryu jujutsu in 1950s in Korea. Choi Yong-sul came back from Japan after learning the art and started spreading. It originally focused on grappling techniques, later combined other technical elements like striking and kicking and shaped current styles.
} 
the established tradition strengthens its position in Korea and it is recognised worldwide, the process of consolidating its position inside Korea is repeated. There is a conflict pertaining to the exclusive rights between traditional martial arts that are recognised on a national level and those that are not. It is highly likely that if the human body and codified techniques concerning it are managed by state-authorised institutions then the discourse will continue in Korea.

The modern Muyedobotongii is a product of current society's needs, whether by design or accident. Legally, and institutionally, South Korea has policy of promoting new "traditional" martial arts and, as seen with taekwondo and taekkyeon, this state-led martial arts intervention has proven successful. The future still holds numerous questions for the Muyedobotongji and its place in society. Will it share the fate of its predecessors? In this process, what significance will the production and transmission of classical martial arts knowledge found in the Muyedobotognji have? Will it be preserved and revered? Or will it be consumed to meet today's needs?

\section{LIST OF TERMS}

\begin{tabular}{|c|c|c|c|}
\hline & Romanization & $\begin{array}{l}\text { Korean } \\
\text { Classical Chinese }\end{array}$ & Translations \\
\hline \multirow[t]{7}{*}{ Book titles } & Jixiaoxinshu & $\begin{array}{l}\text { 기효신서 } \\
\text { 紀效新書 }\end{array}$ & $\begin{array}{l}\text { New Book of Effective } \\
\text { Discipline }\end{array}$ \\
\hline & Muyejebo & $\begin{array}{l}\text { 무예제보 } \\
\text { 武藝諸譜 }\end{array}$ & $\begin{array}{l}\text { Illustrated Manual of Martial } \\
\text { arts }\end{array}$ \\
\hline & $\begin{array}{l}\text { Muyejebo } \\
\text { Beoyeok Sokjip }\end{array}$ & $\begin{array}{l}\text { 무예제보번역속집 } \\
\text { 武藝諸譜㼑譯續集 }\end{array}$ & $\begin{array}{l}\text { Translated Sequel to } \\
\text { Illustrated Manual of Martial } \\
\text { Arts }\end{array}$ \\
\hline & Muyesinbo & $\begin{array}{l}\text { 무예신보 } \\
\text { 武藝新譜 }\end{array}$ & $\begin{array}{l}\text { New Illustrated Manual of } \\
\text { Martial Arts }\end{array}$ \\
\hline & Muyedobotongji & $\begin{array}{l}\text { 무예도보통지 } \\
\text { 武藝圖譜通志 }\end{array}$ & $\begin{array}{l}\text { Comprehensive Illustrated } \\
\text { Manual of Martial Arts }\end{array}$ \\
\hline & $\begin{array}{l}\text { Shaolin Gunfa } \\
\text { Chanzong }\end{array}$ & $\begin{array}{l}\text { 소림곤법천종 } \\
\text { 少林棍法闡宗 }\end{array}$ & $\begin{array}{l}\text { Exposition of Shaolin Staff } \\
\text { Methods }\end{array}$ \\
\hline & Wubeizhi & 무비지 武備志 & $\begin{array}{l}\text { Treatise on Armament } \\
\text { Technology }\end{array}$ \\
\hline
\end{tabular}




\begin{tabular}{|c|c|c|c|}
\hline & Romanization & $\begin{array}{l}\text { Korean } \\
\text { Classical Chinese }\end{array}$ & Translations \\
\hline \multirow{10}{*}{$\begin{array}{l}\text { Persons' } \\
\text { names }\end{array}$} & Baek Dong-su & 백동수 白東脩 & \\
\hline & Cheng Zongyou & 鄭宗猷 & \\
\hline & Han Gyo & 한교 韓嶠 & \\
\hline & Kim Che-geon & 김체건 金體乾 & \\
\hline & Kim Gwang-suk & 김광석 金光錫 & \\
\hline & Lim Dong-gyu & 임동규 林東圭 & \\
\hline & Mao Yuanyi & 茅元儀 & \\
\hline & Park Je-ga & 박제가 朴齊家 & \\
\hline & Qi Jiguang & 戚繼光 & \\
\hline & Yoon Myung-deok & 윤명덕 尹明德 & \\
\hline \multirow[t]{14}{*}{$\begin{array}{l}\text { Martial arts } \\
\text { terms }\end{array}$} & Bongukgeom & 본국검 本國劍 & $\begin{array}{l}\text { Silla Sword, Korean Native } \\
\text { Sword }\end{array}$ \\
\hline & Gwonbeop & 권법 拳法 & $\begin{array}{l}\text { Fist methods, fist law, bare- } \\
\text { handed techniques }\end{array}$ \\
\hline & Gyeokgu & 격구 擊球 & Polo \\
\hline & Imjin War & $\begin{array}{l}\text { 임진왜란 } \\
\text { 壬辰倭亂 }\end{array}$ & $\begin{array}{l}\text { Japanese Invasions of Korea } \\
\text { in 1591-1598 }\end{array}$ \\
\hline & Jedokgeom & 제독검 提督劍 & Admiral's Sword \\
\hline & Joseon Sebeop & 조선세법 朝鮮勢法 & Joseon Sword Methods \\
\hline & Masangjae & 마상재 馬上才 & Acrobatics on horseback \\
\hline & $\begin{array}{l}\text { Masang } \\
\text { Pyeongon }\end{array}$ & 마상편곤 馬上鞭棍 & Flail on horseback \\
\hline & $\begin{array}{l}\text { Masang } \\
\text { Ssanggeom }\end{array}$ & 마상쌍검 馬上雙劍 & Double swords on horseback \\
\hline & Masang Woldo & 마상월도 馬上月刀 & Moon saber on horseback \\
\hline & Sibpalki & 십팔기 十八技 & $\begin{array}{l}\text { Eighteen Arts, Eighteen Martial } \\
\text { Arts }\end{array}$ \\
\hline & Taekkyeon & 택견 & Korean kicking game \\
\hline & Waegeom & 왜검 倭劍 & Japanese sword \\
\hline & Yedo & 예도 銳刀 & Sharp Saber \\
\hline
\end{tabular}


- Korean romanization observes Revised Romanization of Korean (RR, also called South Korean or Ministry of Culture (MC) 2000) which is the most commonly used and widely accepted system of romanization for Korean. The McCune-Reischauer romanization is also widely used, especially in academic areas.

- Chinese terms and names follow the Pinyin romanization system.

\section{BIBLIOGRAPHY}

\section{VII.1. Primary sources}

Mao, Yuanyi (1621), Wubeiəhbi (Treatise of Military Armament) Zhongguo Bingshu Jicheng Vol.27-36 (Beijing: Jiefangjun Chubanshe, 1989)

Park, Je-ga, Lee Deok-mu (1790), Muyedobotongii (Comprehensive Illustrated Manual of Martial Arts) and Han, Gyo (1598), Muyejebo (Illustrated Manual of Martial Arts), Wonbon Muyedobotongji (Seoul: Dongmunsun, 1989)

Cao, Wenming, Ru, Yinghui edit with notes, compiled by Qi, Jiguang (1561), Jixiaoxinshu (New Book of Military Discipline) (18 chapters) (Beijing: Zhonghua Shuju, 2001)

Fan, Zhongyi edit with notes, compiled by Qi, Jiguang (1588), Jixiaoxinshu (New Book of Military Discipline) (14 chapters) (Beijing: Zhonghua Shuju, 2001)

Choi, Gi-nam (1610), Muyejebo Beonyeok Sokjip (Translated Sequel to Illustrated Manual of Martial Arts) (Daegu: Keimyung University Press, 1999)

\section{VII.2. Secondary literature}

Bae, Woo-sung, Jeongjo ui Gunsa Jeongchaek, gwa Uyedobotongii Pyeonchan wi Baegyeong (The Background of the Ompilation of Muyedobotongii in the Later $18^{\text {th }}$ Chosun Dynasty) Jindan Hakbo 91 (Jindan Hankhoe, 2001)

Park, Cheong-jeong, Muyedobotongji Jubae (Translation of the Muyedobotongji with Notes) (Seoul: Dongmunsun, 2007)

Choi, Bok Kyu. "An Introduction to History of Korean Martial Arts" Syllabus of special lecture hosted by the Center for Korean Studies of Leiden University and the Korean Institute for Martial Arts in Leiden University, 23.02.2008

Choi, Bok-kyu, "Taekwondo Jeonsa roseo Taekkyeon Saryo Haeseok" (Complications with the Interpretation of Taekgyeon as a Predecessor of Taekwondo), Taekwondo Journal of Kuk.kiwon, 7/3 (2016), 57-81

Choi, Bok-kyu, "The Dissemination of Japanese Swordsmanship to Korea", Martial Arts Studies Journal, 6 (2018), 27-40

Choi, Bok-kyu, Gwonbeop Baibeul: Gibyo Sinseo reul tonghae bon Gojeon Gwonbeop (Gwonbeop Bible: Translation with Notes of Quanfa Classic of Jixiaoxinshu) (Paju: Hanguk Haksul Jeongbo, 2003) 
Choi, Bok-kyu, Historical Background of the Compilation of Muyedobotongii and the Discourse on the Martial Arts (Doctoral thesis, Department of Physical Education, Seoul National University, 2003)

Choi, Seok-yeong trans. Hobsbawm, Eric J. \& Ranger, Terence edit., Jeontong ui Naljowa Changjo (The Invention of Tradition) (Seoul: Bokyong Munhwa sa, 1995)

Culin, Stewart. Korean games: with notes on the corresponding games of China and Japan (University of Pennsylvania, 1895)

Editorial Committee of Zhongguo Wushu Dacidian, Zhongguo Wushu Da Cidian (Encylopedia of Chinese Martial Arts) (Beijing: Renmin Chubanshe, 1990)

Lim, Dong-gyu, Hanguk ui Jeontong Muye (Korean Traditional Martial Art) (Seoul: Hakmin sa, 1990)

Lim, Dong-gyu, Muyedobotongï Silki Wanyeok (Complete Translation with of Muyedobotongji) (Seoul: Hakmin sa, 1996)

Park Geum-soo, "Joseon Hugi Gongsik Muye Myeongching e daehan Gochal” (An investigation on "Sippalki" the name of official martial art of the Late Chosun Dynasty), Korean Journal of Physical Education 46/5 (2007), 55-65

Park, Gi-dong, Joseon Hugi Muyesa Yongu (A Study on the History of Martial Arts in the Later Choson Dynasty), Doctoral thesis (Department of Physical Education, Sungkyugwan University, 1994)

Li, Guk-no, Sijjeon Uri Geumdo (Truly Transmitted Korean Swordsmanship) (Yongin: Jikji, 2016)

Kim, Gwang-suk, Bongukgeom (Classic Korean Swordsmanship) (Seoul: Dongmunsun, 1995)

Kim, Gwang-suk, Gwonbeop Yogyeol (Secrets of Classic Gwonbeop) (Seoul: Dongmunsun, 1992)

Kim, Gwang-suk, Joseon Changbong Gyojeong (Textbook of Korean Classic Spear and Staff Techniques) (Seoul: Dongmunsun, 2003)

Kim, Gwang-suk, Sim, U-seong, Muyedobotongii Silgi Haeje (A Practical Analysis of Muyedobotongji) (Seoul: Dongmunsun, 1987)

Hobsbawm, Erik, and Terence Ranger, The Invention of Tradition (Cambridge University Press, 1983)

Hwang, Ki, Soobakdo Daegam (An Encyclopedia of Soobakdo) (Seoul: Hanuri, 1970)

Jeong, Jae-seung, Jeontong Muye Taekkyeon (Traditional Martial Art Taekkyon) (Paju: Hankug Haksul Jeongbo, 2008)

National Folk Museum of Korea, Joseon Hugi Mugi Gojeung, Jaehyeon (A Research and Reproduction of Historical Weapons of the Late Joseon) (Seoul: National Folk Museum of Korea, 2003)

Park, Jong-gwan, Song Deok-gi, Jeontong Musul Taekkeyeon (Traditional Martial Arts Taekkyeon) (Seoul: Seorim Munhwasa, 1983) 
Kim, Sang H., The Comprehensive Illustration of Martial Arts of Ancient Korea (Hartford: Turtle Press, 2000)

Shin, Seong-dae, Mudeok (Martial Virtues) (Seoul: Dongmunsun, 2006)

Lee Seung-kyu, Geundae Sinche Munhwa Hyeonseonggwa Ilje Gangjeom-gi Hakgyo Cheyuk. (The Formation of Modern Physical Culture and Physical Education in School under the Rule of Japanese Imperialism) (Doctoral thesis, Department of Physical Education, Korea University, 2012)

Lee, Seung-soo, "Muye Wonhyeong-ui Jedohwa" (The Systemization of Martial Arts: Focused on Taekkyun), The Korean Journal of History for Physical Education, Sport, and Dance, 14/3 (2009)

Lee, Seung-soo, Mubyeong Munbwajae Taekkyun Jeonseungja-ui Gyebo-e Gwanban Yeongu (The Lineage Study of Taekkyun Performers) The Korean Journal of History for Physical Education, Sport, and Dance, 14(1) (Korea Society for History of Physical Education, Sport, and Dance, 2009)

Shils, Edward, Tradition (Chicago: The University of Chicago Press, 1981)

Shun, Inoue, "The Invention of the Martial Arts: Kano Jigoro and Kodokan Judo", in Mirror of Modernity: Invented Traditions of Modern Japan, ed. By Stephen Vlastos (Berkeley and Los Angeles: University of California Press, 1998), pp. 163-173

Jung, Soo-jin, Hanguk Mubyeong Mnhwajae Jedo-ui Seonglip: Geu Saboejeok Jogeone Gwnaban Yeongu (Constitution of Intangible Cultural Properties Institution in Korea: AStudy on its Social Condition) (Doctoral thesis, Department of Sociology, Sogang University, 2003)

Swope, Kenneth M., A Dragon's Head and a Serpent's Tail: Ming China and the First Great East Asian War, 1592-1598 (Norman: University of Oklahoma Press, 2009)

Kim, Wi-hyeon, Gukyeok Muyedobotongii (Korean Translation of Muyedobotongii) (Seoul: Minjok Munhwa sa, 1984)

Wile, Douglas. Lost T'ai Ch'i Classics from the Late Ch'ing Dynasty (Albany: State University of New York Press (SUNY), 1996)

Wile, Douglas. T'ai Chi's Ancestors (New City: Sweet Ch'i Press, 1999)

$\mathrm{Na}$, Young-il, Roh, Young-koo, Yang Jeong-ho, Choi Bok-kyu, Joseon Junggi Muyeseo Yeongu: Muyejebo, Muyejebo Beonyeok Sokjip Yeokju (A Study on the Illustrated Manuals of Military Arts in the Mid-Joeon Period) (Seoul: Seoul Nation University Press, 2006)

Roh, Young-koo, Joseon Hugi Byeongseo wa Jeonbeop ui Yeongu (Military Tactical Manuals and Military Strategies Written and Devised in the late Chosun Dynasty), Doctoral thesis (Department of Korean History, Seoul National University, 2002)

Kim, Young-oak, Taekwondo Cheolhakui Guseong Wonli (Principles Governing the Construction of the Philosophy of Taekwondo) (Seoul: Tongnamu, 1990) 


\section{VII.3. Online resources}

Encyclopedia of Korean Culture, online: $<$ https://encykorea.aks.ac.kr/ $\geq$ accessed 13.02.2020

Go, Young, Eumsik. Geulssengi, Geureoke Swinngeo Animnida (Food Writing, It is not an Easy Job) The SisaIn, online: $<$ https:/ $/$ www.sisain.co.kr/news/articleView.html?idxno $=34045 \geq$ accessed 25.01.2020

Kim, Yong-ae, Nomination Form International Memory of the World Register: $M u$ Ye Do Bo Tong Ji,

online: < http://www.unesco.org/new/fileadmin/MULTIMEDIA/HQ/CI/CI/pdf $\angle$ mow/nomination forms/dprkorea tong eng.pdf $\geq$ accessed 17.08.2020

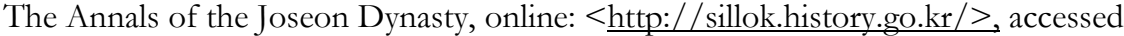
21.09.2019

The Daily Records of Royal Secretariat of Joseon Dynasty, online: < http://sjw.history.go.kr/>, accessed 11.12.2019

The Kyeonggi Ilbo, online: <http://www.kyeonggi.com/news/articleView.html?idxno=2001782>, accessed 15.11.2019

Unesco Memory of the World,

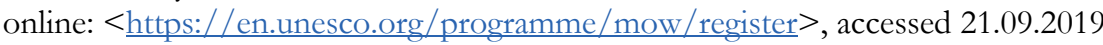

Yuk, Tae-an, Jungguk musul bekekin Muyedobotongji (Muyedobotongij, a Copy of Chinese Martial Arts) Sisa Journal, online: <http://www.sisajournal.com/news/articleView.html?idxno=104950>, accessed 25.01.2020 